\title{
5. Adapting governance and regulation of the marine Arctic
}

\section{Erik J. Molenaar}

\section{INTRODUCTION}

The Arctic is currently undergoing change at a pace many would not have considered possible just a decade or so ago. It is therefore reasonable to argue that while the international law and policy regime for the governance and regulation of the marine Arctic may have been adequate for an ice-dominated environment that allows very little human activity for most of the year, once the marine Arctic becomes increasingly similar to regional seas in other parts of the world for ever longer parts of the year, the adequacy of the old regime can no longer be assumed.

The need for adapting the international regime for the governance and regulation of the marine Arctic to the rapidly changing reality is not really questioned; not even by the Arctic Ocean coastal states. Views diverge, however, on the most suitable pathway for adaptation and its final outcomes. This is at least in part caused by diverging views on the future of the Arctic. While some have advocated more ambitious future change (for example a new overarching Arctic treaty), the Arctic Council argues for incremental change by means of developing the so-called 'Arctic Council System' (ACS). These forward-looking issues are examined in this chapter. After outlining broad support for the need for change in Arctic marine governance and regulation, the chapter discusses evidence that adaptation of governance and regulatory mechanisms is actually already underway.

For the purpose of this chapter, the term 'regime' is used to denote both an instrument and its institutional component. There are no generally accepted geographical definitions for the terms 'Arctic', 'marine Arctic' and 'Arctic Ocean'. For the purpose of this chapter, the term 'Arctic' has an identical meaning as the term 'AMAP area' adopted by the Arctic Monitoring and Assessment Programme (AMAP) of the Arctic 
Council (see AMAP website, http://www.amap.no). The waters within the AMAP area are in this chapter referred to as the 'marine Arctic', and the 'Arctic Ocean' as the marine waters north of the Bering Strait, Greenland, Svalbard and Franz Josef Land, excluding the Barents Sea. There are five coastal states to the Arctic Ocean, namely Canada, Denmark/Greenland, Norway, the Russian Federation and the United States (or: 'Arctic five'). These five plus Finland, Iceland and Sweden are 'Arctic states' (or: 'Arctic eight') by virtue of being defined as such in the 1996 Declaration on the Establishment of the Arctic Council (Ottawa Declaration $)^{1}$ by which the Arctic Council was established.

\section{THE LAW OF THE SEA AND THE ARCTIC}

The international law of the sea is made up of a multitude of global, regional and bilateral instruments, decisions by international (intergovernmental) organizations and international rules from other sources, including customary international law. The 1982 United Nations Convention on the Law of the Sea (LOS Convention; 1833 United Nations Treaty Series 396) functions as the cornerstone instrument at the global level. After its entry into force in 1994, two implementation agreements entered into force; namely the 1994 Part XI Deep-Sea Mining Agreement (1836 United Nations Treaty Series 42) and the 1995 Fish Stocks Agreement (2167 United Nations Treaty Series 3). The LOS Convention currently has 166 parties, the Part XI Deep-Sea Mining Agreement 145 parties and the Fish Stocks Agreement 81 parties. All Arctic states are parties to these three treaties, except for the United States, which is not a party to either the LOS Convention or the 1994 Part XI Deep-Sea Mining Agreement. The United States is therefore, among other things, not subject to the LOS Convention's Part XV on dispute settlement. $^{2}$

Except for archipelagic waters, ${ }^{3}$ all the maritime zones recognized in the LOS Convention also exist in the marine Arctic: internal (marine) waters, territorial seas, contiguous zones, exclusive economic zones (EEZs), (outer) continental shelves, the so-called 'Area' (the deep seabed beyond continental shelves) and the high seas. There are four high seas pockets (or 'enclaves') in the marine Arctic, namely the so-called 'Banana Hole' in the Norwegian Sea, the so-called 'Loop Hole' in the Barents Sea, the so-called 'Donut Hole' in the central Bering Sea, and the so-called 'Central Arctic Ocean'. There may be two or more pockets of the Area that could remain in the Arctic Ocean. Some region-specific 
maritime zones exist as well, as Norway has - instead of a regular EEZ established a Fishery Zone around Jan Mayen and a Fisheries Protection Zone around Svalbard (Molenaar 2012a).

\section{INTERNATIONAL DISPUTES IN THE ARCTIC}

From the perspective of international law, the Arctic and the Antarctic are radically different. The Arctic is not subject to a comparably fundamental disagreement on sovereignty over territory such as exists in the Antarctic. The only dispute on title to land territory in the Arctic is that between Canada and Denmark/Greenland on the tiny Hans Island in the Nares Strait. ${ }^{4}$ News reports in April 2012 suggested that the dispute would soon be resolved by means of dividing the island in two, ${ }^{5}$ but by September 2013 the dispute had still not been concluded.

It is true that there are several unresolved maritime boundaries in the marine Arctic and that most of the outer limits of the continental shelves still have to be established. But that is true for most regions in the world. There are two Arctic-specific areas of interest, however. First, the disagreement between Canada and the Russian Federation on the one hand and the United States and other states - including several EU Member States - on the other hand, on the legal status of the Northwest Passage and other waters within the Canadian Arctic Archipelago and the waters within the Northern Sea Route, respectively (Bartenstein 2011). Second, the disagreement between Norway and several other parties to the 1920 Treaty concerning the Archipelago of Spitsbergen (2 League of Nations Treaty Series 7) as to whether or not the treaty also applies seaward of the territorial sea (Molenaar 2012a).

Apart from these disputes, therefore, the marine Arctic is not fundamentally different from most other marine areas or oceans; except of course the waters adjacent to the Antarctic continent. As all other states have rights under the international law of the sea in all coastal states' maritime zones, the coastal states to the marine Arctic do not have full jurisdiction and control over these areas. In other words: they cannot just do as they please because they have to respect the rights of other states. 


\section{THE NEED FOR ADAPTATION OF THE INTERNATIONAL LAW AND POLICY REGIME FOR THE GOVERNANCE AND REGULATION OF THE MARINE ARCTIC}

All the global instruments that are part of the law of the sea apply to the marine environment of the entire globe; including therefore the entire marine Arctic, however defined. The mandate of the global bodies associated with these instruments has the same geographical scope. The perception, in some parts of the global media, that there is an international law vacuum in the Arctic, which only became apparent due to the melting of ice and the planting of a Russian flag on the seabed of the North Pole in August 2007, is therefore incorrect. The real problems are the gaps and shortcomings in adherence to global instruments, and their implementation at the national and regional levels.

The LOS Convention and the Fish Stocks Agreement are in many ways framework conventions and do not contain the substantive standards that are necessary for actual regulation, for instance safety standards to deal with cases like the sinking of the Titanic or restrictions to prevent overfishing of target species or by-catch of non-target species like dolphins, turtles or birds. Regulation by states individually cannot provide effective solutions for human activities with an inherent or potential transboundary dimension, and multilateral cooperation at the appropriate level is therefore essential. This actually applies to most human activities, both at sea and on land; for instance international shipping, fisheries and offshore hydrocarbon activities as well as cities, industrial activities and agriculture that produce pollutants that end up in the sea through rivers or the atmosphere.

Which level of regulation - bilateral, (sub-)regional or global - is appropriate depends mainly on the activity itself. Activities that are not confined to the regional level, for instance international merchant shipping and activities that produce greenhouse gases, are often best regulated at the global level. Regional regulation can for instance be necessary due to the spatial distribution of particular species or habitats, or the spatial reach of land-based and/or marine pollution. Enclosed or semi-enclosed seas like the Black and Mediterranean Seas are obvious candidates for regional approaches. Regional regulation may also be able to create a level playing field and regional uniformity, which could be attractive to companies that operate in multiple jurisdictions or consider doing so. 
While calls for adapting the international regime for the governance and regulation of the marine Arctic to the new and likely future realities triggered by climate change came initially from academia, nongovernmental organizations (NGOs) and non-Arctic entities, the need for adaptation is now no longer questioned by Arctic states either. The Arctic Council's Ministerial Meeting in Nuuk (May 2011) forms one of the most recent steps in a process of adaptation. The Arctic Council adopted the 'Framework for Strengthening the Arctic Council' - which includes 'The criteria for admitting observers and role for their participation in the Arctic Council' (Annex 1 to the Report of the May 2011 Senior Arctic Officials (SAOs) Meeting) - and reached agreement on a standing Arctic Council secretariat in Troms $\varnothing$, to be formally established in early 2013. Two new Task Forces were also established: one on Institutional Issues (TFII) 'to implement the decisions to strengthen the Arctic Council' and one on Marine Oil Pollution Preparedness and Response (MOPPR Task Force).

The convening of the Nuuk Ministerial Meeting was also used as the occasion for the signature of the 2011 Agreement on Cooperation in Aeronautical and Maritime Search and Rescue in the Arctic (Arctic SAR Agreement). Even though the Arctic SAR Agreement was merely negotiated under the auspices of the Arctic Council - and therefore not adopted by it - it is nevertheless the first legally binding international instrument negotiated by the eight members of the Arctic Council. The successful conclusion of these negotiations reflects a clear determination to strengthen the international regime for the Arctic. A further step in that regard was the MOPPR Task Force, which engaged in negotiations aimed at the adoption of a legally binding instrument for signature at the 2013 Ministerial Meeting in Kiruna.

Further evidence of the acknowledgment of the need for adaptation is the Arctic Ocean Review (AOR) project that is currently carried out within the Council's Protection of the Arctic Marine Environment (PAME) working group. Phase II of that project is intended to culminate in a final report that will

summarize potential weaknesses and/or impediments in the global and regional instruments and measures for [the] management of the Arctic marine environment; outline options to address these weaknesses and/or impediments; and, make agreed recommendations to help ensure a healthy and productive Arctic marine environment in light of current and emerging trends. (AOR project Phase I Report 2009-2011, p. 3; available at http://www. pame.is) 
The sensitive nature of the project is among other things reflected by the fact that it is co-led by five of the eight Arctic Council Members (Canada, Iceland, Norway, the Russian Federation and the United States). While the Phase II Report is intended to be approved by the 2013 Ministerial Meeting, the SAOs have indicated that the final draft of the Phase II Report needs to be submitted well in advance in order for them to review the report and policy recommendations (Report of the November 2011 SAOs Meeting, p. 9).

Finally, the need for adaptation is also implied in the Ilulissat Declaration of 28 May 2008 issued by the Arctic Ocean coastal states. The primary purpose of the Declaration was to dismiss the perception that the Arctic region had become the arena for the last land-grab on earth and that this was occurring in an essentially legal vacuum, with a high risk of potential armed conflict. That such a legal vacuum existed was dismissed by pointing to the presence of the framework of the international law of the sea and a commitment to abide by it. The Declaration then continued as follows: 'This framework provides a solid foundation for responsible management by the five coastal States and other users of this Ocean through national implementation and application of relevant provisions. We therefore see no need to develop a new comprehensive international legal regime to govern the Arctic Ocean.'

While the Arctic five therefore do not support a specific type of adaptation, the remainder of the Declaration reveals a clear commitment for the development of bilateral and multilateral instruments on maritime safety, vessel-source pollution and search and rescue, both within and outside international bodies such as the International Maritime Organization (IMO) and the Arctic Council. The need for adaption is thus not questioned, but only certain outcomes and thereby the pathways connected to such outcomes.

\section{PATHWAYS FOR ADAPTATION AND THEIR OUTCOMES}

\subsection{Introduction and Key Preliminary Choices}

This section examines the suitability of various pathways and outcomes that could be used for addressing gaps and shortcomings in the current Arctic regime. It is useful in that regard to distinguish between adaptation that addresses a specific gap, adaptation of an entire sector, and adaptation at the highest level, which would determine the future regime's ability to engage in holistic, cross-sectoral governance and regulation. 
The negotiations on the Arctic SAR Agreement and the Arctic MOPPR Agreement are examples of issue-specific adaptation, and sectoral adaptation is for instance pursued by means of the negotiations on a mandatory code for polar shipping within IMO.

It is adaptation at the holistic, cross-sectoral level that will be focused upon here. The international community is generally convinced of the merits of holistic, cross-sectoral governance and regulation. That this is not different in the Arctic Council is reflected by the prominence of 'integrated management' and the associated terms 'holistic' and 'ecosystem-based' in the 'Common Objectives' of the Norwegian, Danish and Swedish Arctic Council chairmanships (2006-13), the prominence of Integrated Oceans Management (IOM)/Ecosystem-Based Management (EBM) in the Arctic Council's AOR project and the establishment of the EBM Expert Group by the 2011 Ministerial Meeting.

As regards the pathway, the Members of the Arctic Council - and presumably also the Permanent Participants - currently prefer it to be gradual and incremental rather than a complete overhaul. This approach reflects a recognition of the many uncertainties and diverging views on Arctic futures and warrants use of the term 'strengthening' instead of terms like 'reform', which are more often associated with a complete overhaul.

As regards the adaptation's final outcome, the following seem to be key preliminary choices:

1. Should the Arctic Council be the primary body in the future regime for holistic, cross-sectoral governance and regulation or should another international body be established alongside the Council? The latter is unlikely in light of the significant progress in strengthening the Arctic Council made at the 2011 Ministerial Meeting. Meetings of the Arctic Ocean coastal states are both logical and appropriate in view of common rights and obligations, and are therefore likely to continue, albeit at a more 'technical' level. However, the Arctic five do not currently challenge the preeminence of the Arctic Council (Pedersen 2012).

2. Should the role of Permanent Participants in the future Arctic Council be the same as it is now, or should it be downgraded or, rather, upgraded?

From the perspective of Arctic indigenous peoples - whose unique status in the Arctic Council as Permanent Participants is created to provide for their 'active participation' and 'full consultation' (Arctic Council's Rules of Procedure, Rule 5) - an Arctic treaty can be problematic. Treaty negotiation processes and Rules of Procedure 
of inter-governmental organizations normally give organizations of indigenous peoples the status of NGOs or a similar status, and thereby offer them limited influence. Yet, it can be assumed that the current law on inter-governmental organizations does not prevent states from granting indigenous peoples a status in an intergovernmental organization that is similar to the status that Permanent Participants currently have in the Arctic Council.

3. Should participation by non-Arctic states and entities in a future Arctic Council remain as it is now, or should their participatory status be upgraded?

The Ottawa Declaration and Rule 7 of the Arctic Council's Rules of Procedure stipulate that only Members are entitled to participate in formal decision making. Permanent Participants do not have such a right either, but nevertheless have considerable influence on that process in line with the purpose for which their status was granted. Whereas the Rules of Procedure address the possibility of new Permanent Participants or Observers, the admission of new Members - whether states or entities like the EU - is not envisaged. To a large extent, therefore, the Council is currently a 'closed' body. But this is not inconsistent with current international law.

Assumptions of inconsistency are sometimes caused by incorrect assumptions on the similarity between the Arctic Council and the Antarctic Treaty System (ATS). Article XIII of the 1959 Antarctic Treaty (402 United Nations Treaty Series 71) allows in principle any state to accede, and the status of Antarctic Treaty Consultative Party can, pursuant to Article IX(2) of the Antarctic Treaty, in principle be granted to any state as well. However, in view of the Council's current mandate and main approaches, current international law does not provide a clearly applicable and unqualified entitlement to non-Arctic states and entities to become a Member. This could be different if the Arctic Council would commence regulation in a domain where non-Arctic states and entities have rights under international law (of the sea), for instance in relation to marine capture fisheries (Molenaar 2012b).

4. Should the Ottawa Declaration be replaced by a new overarching regional instrument and, if so, should it be legally binding?

Sooner or later, replacement of the Ottawa Declaration appears inevitable. The formal establishment of the standing Arctic Council secretariat and the amended Rules of Procedure - which inter alia incorporate the Nuuk Observer Rules - is certainly possible by means of a decision by a Ministerial Meeting or a Deputy Ministerial Meeting. But further steps in the process of strengthening the 
Arctic Council - especially if that involves additional institutional change - will eventually generate a need for a new instrument that reflects the desired state of play. The Arctic Parliamentarians are among those that support the evolution of the Arctic Council into a full-fledged international organization established by a treaty, which would then necessarily replace the Ottawa Declaration. ${ }^{6}$

The following subsections consider options for substantive outcomes from these discussions.

\subsection{Elements of the Antarctic Treaty System}

The initial discourse on adaption of the international legal regime of the Arctic seems to have been dominated to a significant extent by assumptions that the Antarctic Treaty or the ATS should be used as a model (Koivurova 2008). ${ }^{7}$ Following lobbying from environmental groups, the European Parliament (EP) was among those that made proposals for adaptation based on that assumption. One of the key operative paragraphs in the EP's Resolution of 9 October 2008 on 'Arctic governance', suggests that

the Commission should be prepared to pursue the opening of international negotiations designed to lead to the adoption of an international treaty for the protection of the Arctic, having as its inspiration the Antarctic Treaty, as supplemented by the Madrid Protocol signed in 1991, but respecting the fundamental difference represented by the populated nature of the Arctic and the consequent rights and needs of the peoples and nations of the Arctic region; believes, however, that as a minimum starting-point such a treaty could at least cover the unpopulated and unclaimed area at the centre of the Arctic Ocean.

It is striking that the resolution acknowledges the difference between the Arctic and the Antarctic on the issue of population, but makes no mention of the fundamental difference on the issue of sovereignty over land territory.

The European Commission's Communication on The European Union and the Arctic Region (Arctic Communication; COM (2008) 763, of 20 November 2008) published in November 2009 was not supportive of an Arctic treaty (p. 10); let alone one along the lines of the Antarctic Treaty. The latter option was also explicitly dismissed by the United States in its Arctic Region Policy (National Security Presidential Directive/NSPD-66 \& Homeland Security Presidential Directive/HSPD25 , of 9 January 2009, at section $\operatorname{III}(C)(3))$. But this did not discourage 
factions within the EP from pursuing the option of an Arctic treaty further by means of the 30 March 2009 Joint Motion for an EP Resolution on 'the international treaty for the protection of the Arctic' (EP doc. RC-B6-0163/2009, of 30 March 2009). Operative paragraphs (1) and (3) of this Joint Motion are particularly troubling and read as follows:

1. Calls on the Council and Commission to initiate international negotiations for the adoption of an international treaty for the protection of the Arctic, along the lines of the existing Antarctic Treaty, in order to make the Arctic a zone of peace and cooperation reserved solely for peaceful activities and free of disputes over sovereignty;

3. Calls on the Commission and Council to work towards establishing a moratorium on the exploitation of geological resources in the Arctic for a period of 50 years pending fresh scientific studies.

Compared to the EP's Resolution of 9 October 2008, these ideas are much more inappropriate and unrealistic for the Arctic and therefore entirely unacceptable for Arctic states. Approval of the Joint Motion would almost certainly have further undermined the EU's credibility in the Arctic arena and thereby its chance for obtaining Observer status with the Arctic Council. The prospects for success on this were already bleak as the EU was during the same period considering the adoption of import restrictions on seal products. These were also actually adopted in September 2009 (Regulation (EC) No 1007/2009, of 16 September 2009, on trade in seal products), triggering action by Canada and Norway which ultimately led to the establishment of a single Panel by the World Trade Organization (WTO)'s Dispute Settlement Body. ${ }^{8}$ The EP's debate on the Joint Motion took place in early April 2009 and featured an appearance by Commissioner Ferrero-Waldner, who expressed concerns that adoption of the Joint Motion would harm the EU's interests. This may well have played a critical role in creating an EP majority in support of adjourning a vote on the Joint Motion. No further action has been taken on the Joint Motion since then.

On 8 December 2009, the EU Council adopted its 'Council conclusions on Arctic issues' (2985th Foreign Affairs Council Meeting), which do not refer to an Arctic treaty at all and approach the issue of adaptation similar to the European Commission's Arctic Communication (p. 3, para. 10). The next EU initiative relevant to Arctic governance is the EP's Resolution on 'A sustainable EU policy for the High North' (2009/ 2214(INI)), of 20 January 2011. The Resolution's Explanatory Statement 
acknowledges that an Arctic treaty along the lines of the Antarctic Treaty 'is not only not promoted by peoples and states in the Arctic', but would also be inappropriate (p. 19). The Resolution itself does not mention an Arctic treaty at all but merely observes that "existing rules need to be further developed, strengthened and implemented by all parties concerned' (para. 42). While this suggests that the EP is no longer advocating an Arctic treaty as such - let alone one along the lines of the Antarctic Treaty - the procedure on the Joint Motion of 30 March 2009 is formally still pending. There may be Arctic states that interpret this as a sign that the EP may still support this option and may try to get the Joint Motion adopted after all. The EP could therefore consider completing the procedure in a way that would avoid any risk of adopting the Joint Motion. One of the most recent EU initiatives is the Joint Communication 'Developing a European Union Policy towards the Arctic Region: progress since 2008 and next steps' (Doc. JOIN (2012) 19 final, of 26 June 2012), which is compatible with earlier positions of the Commission and the Council on the issue.

It is argued that the calls by the EP and others for adaptation modelled on the Antarctic Treaty or the ATS had several consequences. First of all, it smothered a full and meaningful debate on a new Arctic treaty as such. At many occasions where the option of a new treaty came up, the debate often first focussed on the question as to whether or not the Antarctic Treaty or the ATS are useful models for the Arctic. Once that debate had inevitably led to the conclusion that this question must be answered negatively, much of the available time and energy was already spent. A negative outcome of that debate may even have been confused with the conclusion that no new Arctic treaty whatsoever was an option.

Second, the debate revolved mainly around elements of the Antarctic Treaty or the ATS that were clearly unsuitable for a future Arctic regime, and did not manage to approach the issue from a more positive angle; namely to consider which elements could be suitable. It is therefore argued that such elements include:

1. the linkages between the instruments of the ATS and the bodies established by them, for instance Article 5 of the Protocol on Environmental Protection to the Antarctic Treaty (Madrid Protocol) and Articles III and V of the 1980 Convention on the Conservation of Antarctic Marine Living Resources (CCAMLR Convention; 1329 United Nations Treaty Series 47). It is submitted that these linkages are conducive to holistic, cross-sectoral regulation;

2. the notion that activities must be planned and undertaken on the basis of adequate information and prior assessments - including in 
certain situations environmental impact assessments (EIAs) - as laid down in Articles 3 and 8 of, and Annex I to, the Madrid Protocol;

3. the notion that certain areas need special protection for various purposes, as laid down in Annex V to the Madrid Protocol;

4. the precautionary and ecosystem approaches to fisheries management developed by the Commission for the Conservation of Antarctic Marine Living Resources (CCAMLR) pursuant to Article II(3) of the CCAMLR Convention, including the CCAMLR Ecosystem Monitoring Program; and

5. the mandate of Antarctic Treaty Consultative Parties (ATCPs) as a so-called 'default authority', namely an essentially unlimited mandate/authority that can be used in scenarios where no other competent international body exists.

But as references to the Antarctic Treaty or the ATS are more likely to undermine than to help proposals to include similar elements in the future Arctic regime, it is probably more effective to refer to other international instruments or regimes that contain similar elements. For instance, another international body with default authority is the OSPAR Commission established by the 1992 Convention for the Protection of the Marine Environment of the North-East Atlantic.

\subsection{A New Framework Instrument for the Marine Arctic}

In May 2008, the Arctic Ocean coastal states made it clear by means of the 2008 Ilulissat Declaration that they saw 'no need to develop a new comprehensive international legal regime to govern the Arctic Ocean'. Not long before, the World Wide Fund for Nature (WWF) had called for a 'regional agreement on the management and conservation of the Arctic marine environment' (Huebert and Yeager 2008). Later in 2008, WWF commissioned additional research from Timo Koivurova and the present author, which eventually led in 2010 to a report containing a proposal for a new framework instrument for the marine Arctic (Koivurova and Molenaar 2010).

This report outlines the negotiation of a regional framework instrument for the marine Arctic pursuant to which the Arctic Council is transformed into an overarching strategic plenary body, assisted by one or more advisory bodies (for example an Arctic Monitoring and Assessment Committee) and complemented by one or more sectoral regulatory Commissions, which would be established by separately negotiated 
Protocols to the framework instrument (for example on fisheries, shipping or offshore hydrocarbon activities). In order to safeguard the sovereignty, sovereign rights and jurisdiction of Arctic Ocean coastal states, the regulatory Commissions would not be strictly subordinate to the Arctic Council. The proposal identifies the main elements of the envisaged framework and offers alternatives on many issues, such as the instrument's spatial scope (even though limited to the marine environment) and the sensitive issues of participation and decision making in the Arctic Council and its associated regulatory Commissions.

So far, there is very little, if any, open support among the Arctic eight for a new framework instrument for the marine Arctic. Young (2011) and Stokke (2009) advise against investing time and energy into its negotiation and establishment. For instance, Young (2011) calls attention to the fact that treaties can take a long time to enter into force and uses the LOS Convention as an example, even though most treaties take much less time. Rather than offering a concrete alternative, he essentially embraces a laissez faire attitude and relies strongly on the willingness and ability of Arctic states to pursue issue-specific and sector-specific adaptation. While the operationalization of EBM in the Arctic is eventually identified as the biggest challenge, no guidance is offered as to how this challenge should be met.

\subsection{A Strengthened Arctic Council Operating in an Arctic Council System}

The 2011 Nuuk Ministerial has made it clear that the Arctic Council currently pursues a two-tiered approach on adaptation. The first tier consists of strengthening the Arctic Council, for instance through a standing Arctic Council secretariat and assessed contributions. The second tier consists of issue-specific adaptation through the negotiation of (non-)legally binding international instruments under the auspices of the Arctic Council; namely, the Arctic SAR Agreement and the outcome of the negotiation process conducted by the MOPPR Task Force. In case these negotiation processes culminate in legally binding instruments, these cannot be adopted by the Arctic Council, as it lacks a mandate to do so. The notion of the Arctic Council System (ACS) has been introduced by the present author (Molenaar 2012b) to clarify that legally binding instruments such as the Arctic SAR Agreement, and their institutional component, can be part of the Council's output. This is notwithstanding the fact that they are not formally adopted by the Arctic Council, or indeed could not even be so. 


\section{SUMMARY AND CONCLUSIONS}

As argued in this chapter, while the need for adapting the international legal and policy regime for the governance and regulation of the marine Arctic to the rapidly changing reality is no longer questioned, views diverge on the most suitable pathways for adaptation. This divergence of views relates above all to adaptation at the holistic, cross-sectoral level, and not so much on issue-specific or sector-specific adaptation.

As regards the pathway for adaptation, the Members of the Arctic Council, and presumably also the Permanent Participants, currently prefer it to be gradual and incremental rather than a complete overhaul. As regards the adaptation's final outcome, it seems highly likely that the Arctic Council will be the primary body in the future regime for holistic, cross-sectoral governance and regulation and that the Ottawa Declaration will sooner or later be replaced by a new overarching regional instrument, whether legally binding or not. The roles and participatory status of organizations of Arctic indigenous peoples and non-Arctic states and entities in the future regime is much less obvious and depends above all on the future Arctic Council's mandate, spatial scope and institutional structure. If, for instance, the Arctic Council commences regulation in a domain where non-Arctic states and entities have rights under international law (of the sea) - for instance on marine capture fisheries broader participation could benefit compliance with regulation.

Calls to use the Antarctic Treaty or the ATS as a model for adaptation of the Arctic regime have proved less than fruitful. The Antarctic Treaty and the ATS were above all shaped by the fundamental disagreement on sovereignty over the Antarctic continent. As nothing remotely similar to that exists in the Arctic, such calls are both inappropriate and unrealistic for the Arctic and therefore entirely unacceptable for Arctic states. Moreover, the calls smothered a full and meaningful debate on a new Arctic treaty as such, and thus failed to focus discussion on specific elements of the Antarctic Treaty, or the ATS more generally, that might have been suitable for a future Arctic regime.

In 2008, the Arctic Ocean coastal states declared that they saw 'no need to develop a new comprehensive international legal regime to govern the Arctic Ocean'. While this statement may at the time have been partially aimed at dismissing adaptation modeled on the Antarctic Treaty or the ATS, there seem currently very few Arctic states, if any, that support a new framework instrument for the marine Arctic. The 2011 Nuuk Ministerial has clarified that the Arctic Council currently prefers to pursue a two-tiered approach on adaptation through strengthening the 
Arctic Council as well as negotiating (non-)legally binding international instruments under the auspices of the Council, thereby giving rise to the notion of the Arctic Council System (ACS). The adequacy of this two-tiered approach will depend among other things on the extent of coordination within the ACS and between the ACS and other international bodies as well as the operationalization of EBM.

The future regime for the Arctic must strike an appropriate balance between the rights, obligations and interests of not only Arctic states and Arctic indigenous peoples but also of non-Arctic states and entities and the international community as a whole. This regime should contain the strengths of the Arctic Council, successful elements of other regimes and new elements that are not only tailor-made for the Arctic and the rapid changes it is undergoing, but also avoid the gaps and shortcomings currently experienced by other regional regimes.

\section{NOTES}

1. All Arctic Council Declarations and Reports of Senior Arctic Officials (SAOs) Meetings are available at http://www.arctic-council.org.

2. In the domain of straddling and highly migratory fish stocks, however, the United States is subject to Part XV of the LOS Convention due to its being a party to the Fish Stocks Agreement. See also President Ronald Reagan's Statement on 'United States Ocean Policy', of 10 March 1983, 19 Weekly Comp. Pres. Doc. 383.

3. Terms such as the 'Canadian Arctic Archipelago' and the 'Spitsbergen Archipelago', even if used consistently by Canada and Norway, do not imply that these states qualify - or claim to qualify - as archipelagic states in the domain of the international law of the sea.

4. See the Joint Statement by the then Canadian Minister of Foreign Affairs Pettigrew and then Danish Minister of Foreign Affairs Møller made in New York on 19 September 2005 (available at <news.gc.ca>) and the short article by P.E.D. Kristensen, then Ambassador of Denmark to Canada, published in the Ottawa Citizen on 28 July 2005, which place the dispute in the proper perspective of the good and ongoing cooperation between the two states.

5. News report dated 11 April 2012, available at http://www.nationalpost.com.

6. Cf. Para. 1 of the Conference Statement adopted at the Arctic Parliamentarians' 10th Conference in September 2012 (available at <www.arcticparl.org>), which is based on the Report entitled 'Arctic Governance in an Evolving Arctic Region' drawn up by the Standing Committee of Parliamentarians of the Arctic Region (SCPAR; on file with author).

7. As a recent Nature editorial suggests, the discourse on this still continues (Nature 2012).

8. The Panel was established on 21 April 2011, and the final report was expected by October 2013. 


\section{REFERENCES}

Bartenstein, K. (2011), 'The "Arctic exception" in the law of the sea convention: a contribution to safer navigation in the northwest passage?', Ocean Development \& International Law, 42, 22-52.

Huebert, R. and B.B. Yeager (2008), 'A New Sea. The Need for a Regional Agreement on the Management and Conservation of the Arctic Marine Environment', WWF, available at http://www.panda.org/arctic (accessed on 7 March 2013).

Koivurova, T. (2008), 'Alternatives for an Arctic treaty - evaluation and a new proposal', Review of European Community \& International Environmental Law, 17, 14-26.

Koivurova, T. and E.J. Molenaar (2010), 'International Governance and Regulation of the Marine Arctic. A Proposal for a Legally Binding Instrument', WWF, available at http://www.panda.org/arctic (accessed on 7 March 2013).

Molenaar, E.J. (2012a), 'Fisheries regulation in the maritime zones of Svalbard', International Journal of Marine and Coastal Law, 27, 3-58.

Molenaar, E.J. (2012b), 'Current and prospective roles of the Arctic council system within the context of the law of the sea', International Journal of Marine and Coastal Law, 27, 553-95.

Nature (2012), 'Poles apart. Protecting the Arctic from pollution requires a binding agreement like the Antarctic treaty', Nature, 482, 2 February, 5-6.

Pedersen, T. (2012), 'Debates over the role of the Arctic council', Ocean Development \& International Law, 43, 146-56.

Stokke, O.S. (2009), 'Protecting the Arctic environment. The interplay of global and regional regimes', Yearbook of Polar Law, 1, 349-69.

Young, O.R. (2011), 'If an Arctic ocean treaty is not the solution, what is the alternative?', Polar Record, 47, 327-34. 
